Research Article

\title{
Cloning Method for Stress-Resistant Gene of Conringia planisiliqua under Drought Stress
}

\author{
Yanfei Zhu ${ }^{(D)},{ }^{1}$ Yanying $Q u \mathbb{D}^{1},{ }^{1}$ and Melkamu Teshome Ayana $\mathbb{i D}^{2}$ \\ ${ }^{1}$ College of Agronomy, Xinjiang Agricultural University, Urumqi 830052, China \\ ${ }^{2}$ Department of Hydraulic and Water Resources Engineering, Arba Minch University, Arba Minch, Ethiopia
}

Correspondence should be addressed to Melkamu Teshome Ayana; melkamu.teshome@amu.edu.et

Received 13 May 2021; Revised 1 June 2021; Accepted 3 June 2021; Published 15 June 2021

Academic Editor: Dilbag Singh

Copyright (c) 2021 Yanfei Zhu et al. This is an open access article distributed under the Creative Commons Attribution License, which permits unrestricted use, distribution, and reproduction in any medium, provided the original work is properly cited.

The low temperature, drought, high salt, and other environments influence crop production and development directly, so the gene cloning method has become an effective biological means. In order to effectively improve the cloning effect, a gene cloning method for Conringia planisiliqua based on mRNA differential display technology was proposed. Based on mRNA differential display technology, the gene of Conringia planisiliqua was transcribed. The present study expects gene cloning to be better than the traditional method. This will lay the basis for gene cloning and functional verification of the transcription and disease-resistant proteins in Conringia planisiliqua. According to homologous identification results, the homologous drought-resistant genes were determined and screened. The data of Conringia planisiliqua in the existing biological database were used to extract ESTs data of Conringia planisiliqua. Then, the heating environment was established and the concept of integral function was introduced to express the influence of growth environment of different genomes. The mass, momentum, energy, and turbulent flow situation of stress-resistant gene of Conringia planisiliqua during the growth were satisfied. Finally, the data search was carried out in the NCBI database and gene cloning was achieved by ESTs data sequence. Experimental results show that the proposed method can effectively reduce the gene data fitting and improve the quantity of gene fragments cloned in a cycle, so the overall cloning effect is better.

\section{Introduction}

Low temperature, drought, and saline-alkali conditions affect the yield and quality of crops seriously [1]. How to solve the crop yield reduction caused by these adverse conditions and make use of land resources, water resource is a major issue related to agricultural production. With the rapid development of molecular biology and the maturity of genetic engineering technology, improving the stress resistance of crops through genetic engineering is an effective way to improve crop yield [2]. How to use the resource of stress-resistant genes and find "key genes" from a large number of genes related to osmotic stress is an important precondition for plant osmotic stress genetic engineering. Because the stress resistance of plant is a complex quantitative character and it is also the result of multiple regulatory mechanisms, the transgenic plants with a single functional gene have no significant effect on resistance to osmotic stress [3]. In contrast, the transcription factor gene can regulate the expression of a series of downstream genes by combining with cis-acting elements, so as to achieve the cloning of stress-resistant genes. It is necessary to search for the transcription factors that play an important role in the process of stress resistance and then apply them to stressresistant gene engineering. Thus, the ideal effect can be achieved by gene cloning [4].

Conringia planisiliqua belongs to the cruciferous Conringia, which is an ephemeral plant in early spring. Conringia contains eight species, and there is only one species in Xinjiang and Tibet [5]. It is a cruciferous herb. The height is $30-60 \mathrm{~cm}$. The lower part is covered with single hairs and the upper part is glabrous. It is unbranched [6]. The seed is dark brown and short. The length is about $1.5 \mathrm{~mm}$. It has a narrow edge and heavy hilum colour. The flower season is from May 
to June. It grows on the hillside of low mountain belt and dry riverbed, with an altitude of $900 \mathrm{~m}-1000 \mathrm{~m}$. At present, the researches on ephemeral plants are mainly focused on population classification and seed biology. Conringia planisiliqua belongs to the tribe Brassicaceae in the system. Some researchers find that the chromosome number of Conringia planisiliqua is seven. But the researches on its internal genetic resources mining are not enough. In recent years, PEG6000 is used to simulate drought stress on six ephemeral plants, including Conringia planisiliqua. We can see that Conringia planisiliqua has a strong ability of drought resistance [7]. Some experts have cloned the CpHRD transcription factor gene of Conringia by homologous gene cloning technology and transformed the tobacco. The identification of related physiological indexes of drought resistance shows that the ability of drought resistance of transgenic tobacco with the CpHRD gene is significantly improved [8].

DDRT-PCR technology which was proposed by Japanese biological scientists in 2016 is widely applied in various fields of biotechnology, such as agriculture, plants, animals, medicine, and fungi, involving the gene induction and expression, heterosis mechanism, stress resistance, development molecular mechanism, gene cloning, and so on. In addition, this technology has successfully isolated hundreds of genes [9]. At present, there are few reports on the isolation and utilization of drought resistance genes in Conringia. In order to fully explore and utilize its drought resistance gene resource, it is necessary to research the mechanism of drought resistance mechanism from the molecular level. Therefore, this research uses mRNA differential display technology to select genes related to drought resistance of Conringia. Meanwhile, mRNA differential display technology is used to separate and recover the differentially expressed genes of Conringia under different conditions, then sequence them after the second PCR, and analyze their homology. In addition, the electronic homology cloning method is used to determine the DREB transcription genes of Conringia and find the core fragment of the droughttolerance gene, so as to clone the gene under drought stress. It provides some candidate genes for further cloning of fulllength drought-resistant genes and the breeding for stress resistance.

\section{Methodology}

\subsection{Screening of Drought-Resistant Genes of Conringia planisiliqua Based on mRNA Differential Display Technology}

2.1.1. Gene Transcription and Homology Identification of Different Fragments. Conringia planisiliqua is a special short-lived plant in Xinjiang. This kind of plant lives in arid desert and gravel edge for a long time. In the longterm evolution, it adapts to the arid environment. There is a lack of understanding of the mechanism of stress resistance $[10,11]$. The drought-resistant genes are screened by mRNA differential display. The seeds come from the plant teaching and research section of Xinjiang
Agricultural University, and the seeds are planted and harvested in this laboratory [12]. First of all, the seeds were seeded in vermiculite, pearlite, and soil. The proportion is $1: 2: 3$. They were cultured in the culture room with temperature of $23-25^{\circ} \mathrm{C}$ and light of 4000lx. After they grew to 3-4 weeks and there are 5-8 leaves, they were irrigated with 20\% PEG6000. Then, drought stress treatment and $\mathrm{NaCI}$-simulated salt stress treatment were simulated, and then seedling leaves after $0 \mathrm{~h}, 3 \mathrm{~h}, 6 \mathrm{~h}, 9 \mathrm{~h}$, $12 \mathrm{~h}$, and $24 \mathrm{~h}$ stress were collected [13]. After quickfreezing process with liquid nitrogen, they were stored in a refrigerator at $70^{\circ} \mathrm{C}$. After that, RNA was extracted and purified with Trizol plant extraction kit of Tiangen, based on the instructions [14]. DNA was removed from RNA by DNase I kit. Moreover, 1.2\% agarose gel electrophoresis was used to detect the quality of RNA. The reverse transcription kit and instructions were adopted. The $2 \mu \mathrm{g}$ RNA with four anchored primers is reverse transcribed to the first-strand cDNA (see Table 1).

After diluting the reverse transcript products for 5 times, we adopt $2 \mu \mathrm{L}$ template cDNA. Eighty pairs of PCR amplification primers are composed of four anchored primers and twenty random primers. The reaction system is $20 \mathrm{p} \mu \mathrm{L}$, including $10 \times$ ExTaq Buffer $2 \mu \mathrm{L}, 2.5 \mathrm{mmol} / \mathrm{L}$ dNTP1L, $10 \mathrm{mmol} / \mathrm{L}$ anchor primer $1 \mu \mathrm{L}$, and $10 \mathrm{mmol} / \mathrm{L}$ anchor primer $1 \mu \mathrm{L}$. The $6 \%$ denatured polyacrylamide gel is used to test, and then they are photographed and recorded after colour reaction (see Table 2).

According to Table 2, the homology of different fragments is determined. The carrier sequence is removed by DNAMAN software (version 5.2; Lynnon Biosoft), and then the homology of different fragments is compared and analyzed by BLASTn software on the NCBI website. The closest sequence is used to annotate the biological function. The gene expression of drought and salt treatment is DF-2, DF-6, and DF-14 [15].

7500 Fast Real-Time PCR System is adopted. SYBR Green I fluorescent dye method was used to detect the gene transcription and expression levels of Conringia planisiliqua seedlings treated with 20\% PEG6000 and $200 \mathrm{~mm} \mathrm{NaCI}$ in different time periods.

2.1.2. Filtering Operation. According to the results of RNA electrophoresis detection, the ratio of brightness display can be determined. After that, the detection results of $\mathrm{UV}$ spectrophotometer are recorded, and all records are applied to subsequent analysis (see Figure 1).

The results show that, in eighty primer combinations, the differential bands amplified by the primer pair composed of anchor primers have the best effect. The bands with increased or decreased expression are selected to retrieve and sequence, so that eighteen different bands with good reproducibility are obtained. The size of the band is basically 150-300 by, in which the size of the band is $414 \mathrm{bp}$ and $559 \mathrm{bp}$. The average length of the bands is $231 \mathrm{bp}$. There are eighteen fragments with better specificity in secondary amplification. There are eighteen fragments based on the cloning sequencing (see Figure 2). 
TABle 1: Anchor primers of RNA differential display.

\begin{tabular}{lc}
\hline The name of the primer & Primer sequence 5-3 \\
\hline M1 & ACGACTCACTATAGGGTTTVA \\
M2 & ACGACTCACTATAGGGTTTVG \\
M3 & ACGACTCACTATAGGGTTTVG \\
M4 & ACGACTCACTATAGGGTTTVT \\
\hline
\end{tabular}

TABLe 2: Random primers for mRNA differential display.

\begin{tabular}{ll}
\hline The name of the primer & Primer sequence 5-3 \\
\hline R1 & ACGACTCACTATAGGGTTTVG \\
R2 & ACGACTCACTATAGGGTTTVG \\
R3 & ACGACTCACTATAGGGTTTVG \\
R4 & ACGACTCACTATAGGGTTTVT \\
R5 & ACGACTCACTATAGGGTTTVT \\
R6 & ACGACTCACTATAGGGTTTVG \\
R7 & ACGACTCACTATAGGGTTTVC \\
R8 & ACGACTCACTATAGGGTTTVG \\
R9 & ACGACTCACTATAGGGTTTVA \\
R10 & ACGACTCACTATAGGGTTTVG \\
R11 & ACGACTCACTATAGGGTTTVA \\
R12 & ACGACTCACTATAGGGTTTVH \\
R13 & ACGACTCACTATAGGGTTTVG \\
R14 & ACGACTCACTATAGGGTTTVY \\
R15 & ACGACTCACTATAGGGTTTVG \\
R16 & ACGACTCACTATAGGGTTTVT \\
R17 & ACGACTCACTATAGGGTTTVA \\
R18 & ACGACTCACTATAGGGTTTVG \\
R19 & ACGACTCACTATAGGGTTTVG \\
R20 & ACGACTCACTATAGGGTTTVG \\
R21 & ACGACTCACTATAGGGTTTVG \\
R22 23 & ACGACTCACTATAGGGTTTVG \\
R24 & ACGACTCACTATAGGGTTTVY \\
& ACGACTCACTATAGGGTTTVT \\
\hline
\end{tabular}

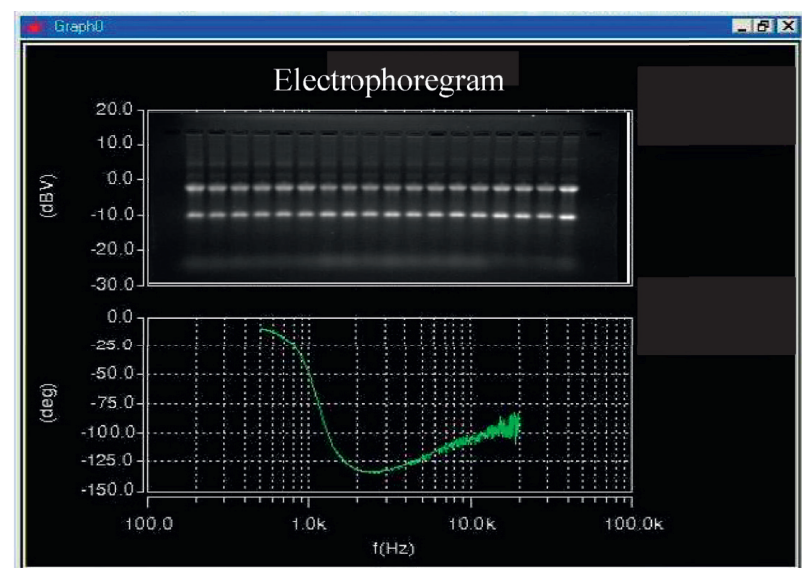

FIgURE 1: Total RNA electrophoresis of Conringia planisiliqua.

According to the results of electrophoresis detection, the sequence similarity is compared. Generally, the categories are as follows:

Based on similarity comparison, they can be divided into the following categories:

(1) Three hypothetical protein-related fragments, hypothetical disease-resistance protein DF-1 of Brassica

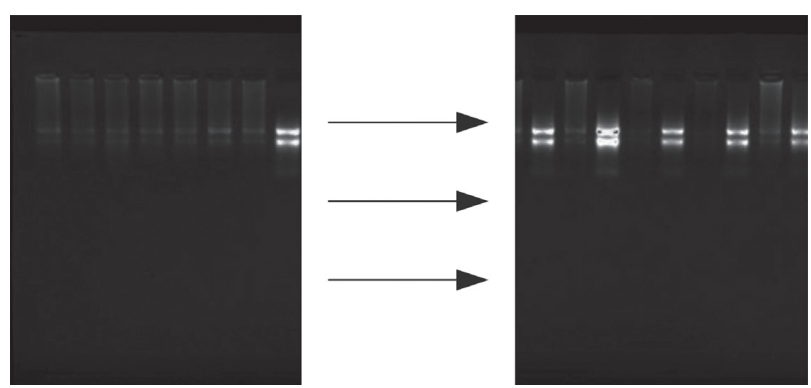

FIGURE 2: Detection results of $6 \%$ electrophoresis of partial CDNA differential bands.

cabbage and hypothetical protein of mountain hollyhock, DF-3 and DF-4 [16].

(2) Seven basic metabolism fragments, including receptor-like protein kinase 37 with a large content of cysteine, DF-5, cabbage vascular bundle protein DF6, protein curvature of chloroplast thylakoid in Brassica campestris 1A, DF-7. Arabidopsis amino acid permeable enzymel mRNADF-8, Brassica campestris amino acid permeable enzyme 1, F-90 Arabidopsis peptidyl prolyl cistrans isomerase CYP63-like family protein mRNA, DF-16, and Brassica napus rich in glutamic acid cell wall structural protein with molecular level 120 .

(3) Three disease-resistant proteins, radish specific albumin 5, DF-2, Arabidopsis AMC7DF-10, and Brassica napus MLO-like protein 12, DF-110.

(4) Two unknown proteins, DF-17 and DF-180.

(5) Two photoperiod-related proteins (CCAL and DF13) in Arabidopsis. GATA transcription factor 13 is assumed in Camelina, DF-15. The GATA transcription factor 13 assumed in Camelina may play a regulatory role in light response genes.

(6) One transcription factor, DF-14, similar fragments of Arabidopsis thaliana alfin-like protein. The details are shown in Table 3.

The research shows that the expression of DF-2 and DF-14 was raised dynamically with time under PEG6000 stress treatment. The expression level of DF-2 reached the highest value at $9 \mathrm{~h}$ and DF-14 reached the highest value at 6 h. DF-6 expression came down by the influence of PE 66000. Under the salt stress, DF-2 and DF-14 were upregulated dynamically with time, and the expression of them reached the highest level at $24 \mathrm{~h}$. DF- 6 was the highest at $3 \mathrm{~h}$, and then it was lower than the contrast. The results show that the response speed of DF- 2 and DF- 14 to the salt stress was slower than that of DF- 6 . Therefore, the expression of DF-2, DF-6, and DF-14 is induced by drought and salt.

According to statistical results, the final gene function and proportion are determined as shown in Figure 3.

According to the gene results shown in Figure 3, based on the relationship between drought stress and salt stress, the fluorescence quantitation is used to determine the overall format of the selected gene segment. See Figure 4. 
TABLE 3: Comparison of DFs sequence and BLAST sequence in NCBI accounting sequence database.

\begin{tabular}{|c|c|c|c|}
\hline Name of the sequence & The length of the function & Match login number & $E$ value \\
\hline DF-1 & Hypothetical disease-resistance protein of Brassica cabbage & $\mathrm{AB} 751520$ & $6 E-27$ \\
\hline DF-2 & Radish specific albumin 5 & AB751521 & $1 E-64$ \\
\hline DF-3 & Hypothetical protein of mountain hollyhock & AB751522 & $7 E-48$ \\
\hline DF-4 & Camelina, receptor-like protein kinase 37 with a large content of cysteine & AB751523 & $5 E-25$ \\
\hline DF-5 & Cabbage vascular bundle protein & AB751524 & $4 E-170$ \\
\hline DF-6 & Protein curvature of chloroplast thylakoid in Brassica campestris 19 & AB751525 & $6 E-66$ \\
\hline DF-7 & Arabidopsis amino acid permeable enzyme $1 \mathrm{mRN} \mathrm{A}$ & AB751526 & $6 E-52$ \\
\hline DF-8 & Brassica cabbage amino acid permease 1 & AB751527 & $3 E-60$ \\
\hline DF-9 & Arabidopsis metacaspase 7 & AB751528 & $1 E-2$ \\
\hline DF-10 & Brassica napus MLO-like protein 12 & AB751529 & $8 E-17$ \\
\hline DF-11 & Brassica napus glutamic acid rich cell wall structural protein 1 & AB7515210 & $6 E-27$ \\
\hline DF-12 & $\mathrm{mRN}$ a of Arabidopsis CCAl protein & AB7515211 & $6 E-30$ \\
\hline DF-13 & mRNA of Arabidopsis thaliana alfin-like protein & AB7515212 & $5 E-42$ \\
\hline DF-14 & Camelina sativa hypothesis GATYA transcription factor 13 & AB7515213 & $4 E-2$ \\
\hline DF-15 & Arabidopsis peptidyl-prolyl cis-trans isomerase CYP63-like family protein mRNA & AB7515214 & $3 E-87$ \\
\hline DF-16 & Hypothetical protein of mountain hollyhock & AB7515215 & $2 E-28$ \\
\hline DF-17 & Unknown characteristic protein ycf39-like & AB7515216 & $6 E-20$ \\
\hline DF-18 & Brassica napus unknown protein & AB7515217 & $1 E-14$ \\
\hline
\end{tabular}

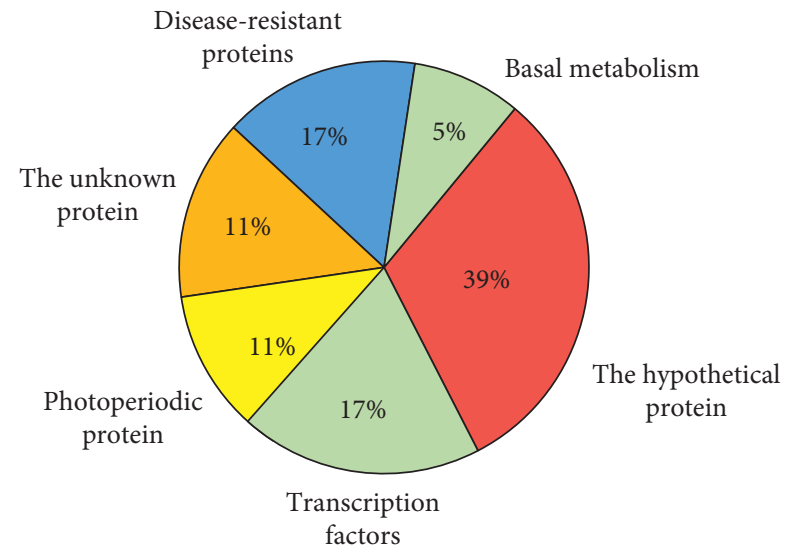

Figure 3: Function classification and proportion.

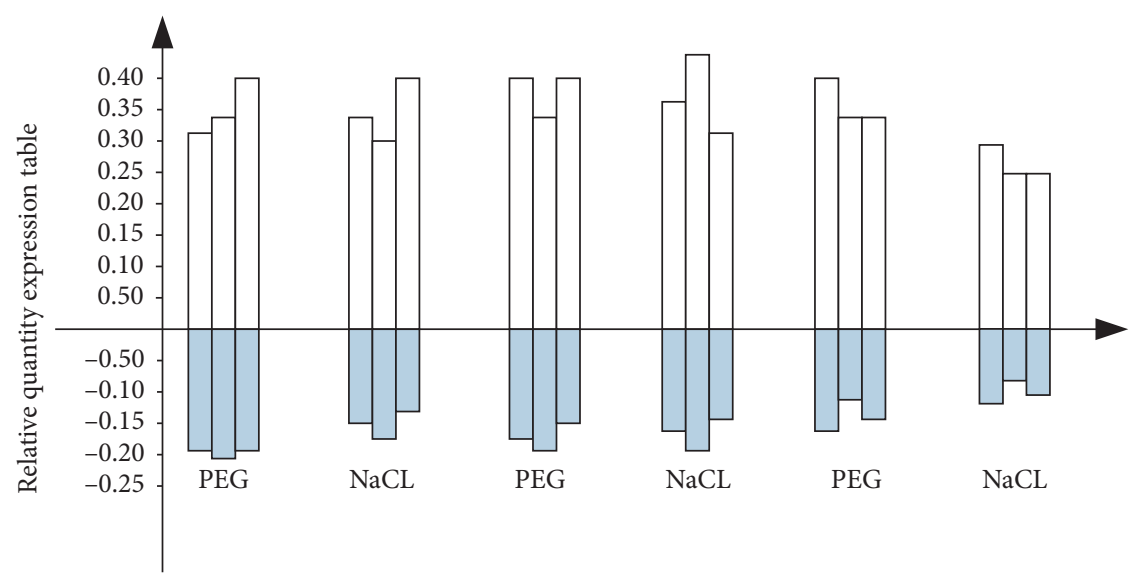

Figure 4: DF-2 DF-6 DF-14 fluorescence expression.

According to the screened genes, we can see that the fragments of genes are generally small, so it is difficult to research the gene further. It is necessary to select the longer fragments with unknown functions for further research. The random combination of the anchor primer Oligo (dT) $M_{2}$ produced the most differential bands, which are recycled from thirty selected strips. Eighteen bands are cloned and sequenced. The positive rate is $60 \%$. 
In terms of the discovered gene classification, the proportion of hypothetical protein was maximum, 38.89\%. Next is the proportion of transcription factors and disease-resistant protein, $16.67 \%$. The proportion of unknown protein is the same as the proportion of photoperiodic protein, $11.11 \%$. The proportion of basic metabolism is $5.56 \%$. This result also shows that related protein kinase, vascular bundle protein, photosynthesis, amino acid permeable enzyme, cistrans isomerase, cell wall structural protein, and transcription factor participate in response to the drought stress. However, the photoperiod and disease-resistance proteins also respond, which was rarely found at present. The stress resistance mechanism of plants is the intercrossing stress. Some genes can participate in the biological and abiotic stress of plants. There are many related researches on the genes of basic metabolism, so it is necessary to research the disease-resistant protein, hypothetical protein, unknown protein, and transcription factor further.

2.2. ESTs Data Acquisition of Conringia planisiliqua. All EST data of wild soybean are downloaded from the EST database (dbEST) of NCBI, and there are 18511 data in total. The Linux sequence analysis platform constructed in this research is adopted and the above gene data is used to remove redundant data. There are 9983 unigene data in total. Contigs of 9983 wild Conringia are compared with 61036 probe groups contained in A Metrix soyabean gene expression analysis chip by BLASTn. The signal changes of chip probe groups are used to annotate the expression changes of corresponding Conringia at the early stage of different permeation stress $(1 \mathrm{~h})$. The upregulated expression is selected at least stress. Meanwhile, the annotation information contains contigs with kinase as the material for further study. For the expression level, eighteen protein kinase ESTs are upregulated under $40^{\circ} \mathrm{C}$ stress. Twenty protein kinase ESTs are upregulated under $\mathrm{NaCI}$ stress. Twenty-seven protein kinase ESTs are upregulated under PEG stress. The nonredundant protein kinase EST based on the partial expression of Conringia is shown in Table 4.

TreEMBL/SWISS-PROT database and GenBank database are used to analyze all kinase contigs by BLAST, and the related literature about the subject is consulted to further predict the function of ESTs. The protein kinase ESTs related to stress signal transduction are selected. In order to ensure the balance of Conringia data and the normality of EST data, it is necessary to design the coupling model with the help of solar indoor light and environment distribution.

The solar active heating room is adopted in the design, and its core conditions are as follows.

Firstly, the air in solar active heating room adopted for Conringia data extraction is the incompressible air, which conforms to BOUTER standard. Secondly, the indoor air environment has the feature of steady-state flow and turbulent flow. Thirdly, this research ignores the thermal radiation between solid walls. Fourthly, there is no obvious air leakage in the designed heating room. According to the above assumptions and nonredundant protein kinase EST data, the turbulence flow equation is added to the environmental construction.

In order to extract the complete gene data, the concept of integral function should be introduced into the extraction environment of the designed heating room to represent the influence of different genome growth environment, so as to meet the quality, momentum, energy, and turbulence situation in the growth process of the stress-resistant gene of Conringia. The key point is the gaseous phase of gene distribution. In the following equations, $p$ and $q$ represent the volume fractions, respectively. Taking the comparison of $q$ and particle phase in the greenhouse as an example, it should satisfy the conservation equation of growth mass:

$$
\begin{aligned}
& \frac{\partial}{\partial t}\left(\alpha_{q} \rho_{q} \vec{v}_{q}\right)+\nabla\left(\alpha_{q} \rho_{q} \vec{v}_{q} \vec{v}_{q}\right)=-\alpha_{q} \nabla P \\
& \nabla \bullet \tau_{q}+\alpha_{q} \rho_{q} \vec{g}+\sum_{p=1}^{n} R+m v-m \vec{v}+ \\
& \left(F_{q}+F_{\text {lift }, q}\right) .
\end{aligned}
$$

In equation (1), $\vec{v}_{q}$ denotes the phase velocity of particle in the current gene. $\alpha_{q}$ denotes the mass transfer process indoor. $\rho_{q}$ denotes the reverse mass transfer process. $q$ is compared with the particle phase of Conringia. Let it satisfy the equation of conservation of momentum:

$$
\begin{aligned}
& \frac{\partial}{\partial t}\left(\alpha_{q} \rho_{q} \vec{v}_{q}\right)+\nabla\left(\alpha_{q} \rho_{q} \vec{v}_{q} \vec{v}_{q}\right)=\alpha_{q} \nabla P \\
& \nabla \bullet \tau_{q}+\alpha_{q} \rho_{q} \vec{g}+\sum_{p=1}^{n} R+m v-m \vec{v} \\
& +\left(F_{q}+F_{\text {lift }, q}+F_{v m, q}\right) .
\end{aligned}
$$

In equations (1) and (2), $\tau_{q}$ is the actual expansion of stress and strain of Conringia. The specific calculation is

$$
\tau_{q}=\frac{\alpha_{q} \mu_{q}\left(\nabla v_{q}+\nabla v_{q}^{T}\right)}{\alpha_{q}\left(\lambda_{q}-(2 / 3)\right)} \mu_{q} .
$$

In equations (2) and (3), $\mu_{q}$ and $\lambda_{q}$ denote the actual maximum shear viscosity and average crimp volume viscosity of gene particle phase in the current extraction environment. $F_{q}$ denotes the external volume stress of indoor air particle phase. $F_{\text {lift, } q}$ denotes the maximum lifting stress of particle phase. $F_{v m, q}$ denotes the actual lubrication force of gene phase wall. $v_{q}^{T}$ denotes the force existing in the current indoor particle phases. At this time, $T$ is the actual turbulent diffusion force.

$q$ term is used to compare the particle phase in greenhouse. Let it meet the energy conservation equation.

$$
\begin{aligned}
& \frac{\partial}{\partial t}\left(\alpha_{q} \rho_{q} \vec{v}_{q}\right)+\nabla\left(\alpha_{q} \rho_{q} \vec{v}_{q} h_{q}\right) \\
& =\alpha_{q} \frac{\partial p_{q}}{\partial t}+\alpha_{q} \rho_{q} \vec{g}+S q+\left(Q p q+m_{p q} h_{p q}-m_{q p} h_{q p}\right) .
\end{aligned}
$$


TABle 4: Nonredundant protein kinase EST based on partial expression of Conringia.

\begin{tabular}{|c|c|c|c|}
\hline Unigene & Induced by & Probe number & Probe annotation \\
\hline CL68076contig 1 & PEG & GMA2544.1 & Pyrophosphate-dependent phosphofructokinase \\
\hline CL997contig 1 & $\begin{array}{c}4 \text { Celsius degrees } \\
\text { NaCL } \\
\text { PEG }\end{array}$ & GMA4354.1 & Glycine max $\mathrm{cv}$ prize protein kinase \\
\hline CL1185contig 6 & $\begin{array}{c}4 \text { Celsius degrees } \\
\mathrm{NaCL} \\
\mathrm{PEG} \\
\end{array}$ & GMA2214.1 & Lectin-like protein kinase \\
\hline CL1235contig 5 & $\begin{array}{c}4 \text { Celsius degrees } \\
\mathrm{NaCL}\end{array}$ & GMA1934.1 & Phosphoribulokinase \\
\hline CL145076contig 1 & $\begin{array}{c}\mathrm{NaCL} \\
\mathrm{PEG} \\
\end{array}$ & GMA2054.1 & Protein kinase \\
\hline CL758contig 1 & $\begin{array}{c}\text { PEG } \\
\mathrm{NaCL} \\
4 \text { degree Celsius }\end{array}$ & GMA1684.1 & Phosphoglycerate kinase \\
\hline CL755contig 1 & $\begin{array}{c}\text { PEG } \\
4 \text { degree Celsius } \\
\mathrm{NaCL}\end{array}$ & GMA2204.1 & Protein kinase \\
\hline CL1230contig 4 & $\begin{array}{r}\text { PEG } \\
\mathrm{NaCL} \\
\end{array}$ & GMA1364.1 & HXK2 ARATH hexokinase 2 \\
\hline CL 1238contig 1 & $\begin{array}{c}\text { PEG } \\
4 \text { degree Celsius } \\
\mathrm{NaCL}\end{array}$ & GMA3784.1 & Leucine-rich repeat transmembrane protein kinase 1 \\
\hline CL 1138contig 1 & PEG & GMA2204.1 & Glycine max choline kinase GmCK2pmRNA \\
\hline CL 1285 contig 1 & $\begin{array}{l}\mathrm{PEG} \\
\mathrm{NaCL}\end{array}$ & GMA1934.1 & Phosphoglycerate kinase \\
\hline
\end{tabular}

In equation (4), $h_{p q}$ denotes the maximum specific heat enthalpy of the current particle phase. $S_{q}$ denotes the hot-gas source generated by drought stress factors. $Q_{p q}$ represents the intensity conversion between gas phase and particle phase in the current environment. $h_{q p}$ denotes the highest enthalpy between gas phase and particle phase.

Different energy equations are introduced into the general turbulence formula to calculate the relationship variables. The general form is as follows:

$$
\operatorname{div}(\rho \nu \phi)=\operatorname{div}(F \phi \operatorname{grad} \phi)+S \phi .
$$

In equation (5), $\operatorname{div}(F \phi \operatorname{grad} \phi)$ is the diffusion term of current turbulent, and $S \phi$ denotes the generalized source term.

The boundary condition of Conringia ESTs data calculation: term value should be added to the actual coupling point of the current indoor convection boundary. Because the drought environment will bring the radiation heat source, the constant heat flow is used to represent the current radiation. The actual lighting condition and air supply temperature condition are added, so as to adjust the corresponding pressure of indoor air return outlet to the initial value, 0 . In addition, additional boundary conditions are not needed to be added to the interface between air fluid and nonfluid in the drought environment simulation. The energy relationship in the current gene coupling process is compared numerically. Under the action of solar radiation, the radiation dispersion will be generated, so it is necessary to simulate based on the above coupling environment.

$$
\begin{aligned}
\frac{\mathrm{d} u_{p}}{d_{t}} & =F_{D}\left(u_{p}-u_{g}\right), \\
\frac{\mathrm{d} v_{p}}{d_{t}} & =F_{D}\left(v_{p}-v_{g}\right), \\
F_{D} & =\frac{18 \mu_{g}}{\rho l D_{p}^{2}} \frac{C_{D}}{R_{e d}}, \\
\frac{\mathrm{d} x}{d_{t}} & =u_{p}, \frac{\mathrm{d} r}{d_{t}}=v_{p} .
\end{aligned}
$$

Equation (6) is the equation of particle phase motion under drought stress. Equation (7) is the orbital equation of particle phase.

During the discrete phase orbit simulation, the current greenhouse structure can be regarded as a bisymmetry structure of rotating axis, so the calculation of control equation is also carried out in the way of two-dimensional symmetry. In this design, N-S equation is used to simulate the discrete phase orbit. The equation is as follows:

$$
\frac{\partial U}{\partial t}+\frac{\partial F}{\partial x}+\frac{\partial G}{\partial y}+H=0 .
$$


In equations $(6)-(8)$,

$$
\begin{aligned}
U & =r(\rho, \rho u, \rho E) T \\
F & =r\left(\rho u, \rho u^{2}-T_{x x}, \rho u v-T_{x r}, \rho E u-T_{x x} u\right)^{T}, \\
G & =r\left(\rho_{v}, \rho_{u v}-T_{r x}, \rho v^{2}-T_{r r}\right)^{T} \\
H & =\left(0,0, \tau_{\theta \theta}, 0\right)^{T}, E=(\gamma-1) \frac{p}{\rho}+\frac{1}{2}\left(u^{2}+v^{2}\right), \\
T_{x x} & =-p-\frac{2}{3} \mu\left(\frac{\partial v}{\partial r}+\frac{v}{r}\right)+\frac{4}{3} \mu \frac{\partial u}{\partial x} \\
T_{r r} & =-p-\frac{2}{3} \mu\left(\frac{\partial u}{\partial x}+\frac{v}{r}\right)+\frac{4}{3} \mu \frac{\partial v}{\partial r} \\
\tau_{\theta \theta} & =-p-\frac{2}{3} \mu\left(\frac{\partial u}{\partial x}+\frac{\partial v}{\partial r}\right)+\frac{4}{3} \mu \frac{v}{r} \\
k_{\mathrm{eff}} & =k_{L}+k_{T}, \\
q^{r} & =-k_{\mathrm{eff}}\left(\frac{\partial T}{\partial r}\right), \\
T_{r x} & =\mu\left(\frac{\partial u}{\partial r}+\frac{\partial v}{\partial x}\right), \\
q_{x} & =-k_{\mathrm{eff}}\left(\frac{\partial T}{\partial x}\right),
\end{aligned}
$$

where $T$ denotes time; $\mu$ denotes the current viscosity coefficient; $\gamma$ denotes the thermal energy ratio in the current environment; $k$ denotes the thermal conductivity in the current room; $x$ is the axial coordinate of discrete phases; $r$ denotes the current radial coordinate; $\rho$ denotes the environmental thermal imagery density; $u$ denotes the axial speed; vrepresents the radial speed; $p$ represents the environmental pressure; $E$ is the internal energy under the action.

Finally, ESTs data are calculated. The definition of Conringia ESTs is as follows:

$$
H L_{n}=K F\left(t-t_{w}\right) \varepsilon .
$$

In equation (10), $F$ is the area unit of the enclosure is based on square meters; $K$ is the heat conduction coefficient of the current drought simulation structure. Generally, the unit is $\mathrm{W} / \mathrm{m}^{2}{ }^{\circ} \mathrm{C}$. $t$ is the designed temperature. $t_{w}$ is the actual outdoor temperature in the current heating. $\varepsilon$ is the current heat load coefficient ratio.
2.3. Achievement of Stress-Resistant Gene Cloning of Conringia planisiliqua. The stress-resistant genes of Conringia extracted above are transcribed into the factor gene library. Because the gene sequence of DREB transcription factor is the seed, Glycine soja is regarded as the restriction word according to ESTs data. The data is searched in the database on NCBI to obtain relevant EST sequence. The sequence of EST was spliced by Contig Express splicing software, and then contigs are compared by BLASTn on NCBI. According to the comparison results, the contigs that may be DREB transcription factor genes are selected to predict the full length and ORF. According to the contig 5 sequence, a pair of primers is designed to verify the accuracy of the splicing result. The primers are also designed at both ends of the extended genome sequence contigs. The target fragments are amplified from RNA of Conringia by RT-PCR, and then they are cloned and sequenced. The sequence of primer design is as shown in Figure 5.

Fill in Bacillus coli for transformation. The steps are as follows:

Step 1 . In the connection product, we add equal volume of IM NaCl.

Step 2. Add the DNA to be transformed into $100 \mu \mathrm{L}$ of competent cells. Then, mix it gently and place it on ice for $30 \mathrm{~min}$.

Step 3. Thermal excitation is performed at $42^{\circ} \mathrm{C}$ for $90 \mathrm{~s}$, then put it back in the ice to cool for 1-2 min, after that, the thermal excitation is performed at $42^{\circ} \mathrm{C}$ for $20 \mathrm{~s}$, then put it back in the ice to cool for 1-2 min 1-2 min, and add $500 \sim 600 \mu \mathrm{L}$ fluid $\mathrm{LB}, 370^{\circ} \mathrm{C}, 180 \mathrm{rpm}$, shaking culture for $45 \mathrm{~min}$.

Step 4. Transfer the transformed competent cells to LB solid medium containing antibiotics $\left(37^{\circ} \mathrm{C}\right.$ preheating). Absorb $100 \mathrm{~L}$ bacterial solution, and use a sterile glass rod with elbow to coat the entire plate with bacterial solution.

Step 5. Invert the experimental plate and culture at $37^{\circ} \mathrm{C}$ for $12-16 \mathrm{~h}$; then the bacterial colony appears.

DNA in tissues is extracted by the method of alkaline lysis procedure. The specific steps are as follows:

(a) Single colonies are selected and inoculated into Sml $L B$ liquid medium containing corresponding antibiotics and cultured overnight at $37^{\circ} \mathrm{C}$ and $200 \mathrm{rpm}$.

(b) Pour $1.5 \mathrm{ml}$ bacterial solution into the centrifuge tube, $12000 \mathrm{rpm}$, centrifuge for $30 \mathrm{~s}$, and remove the supernatant.

(c) Add $100 \mu \mathrm{L}$ cold solution I and the oscillates to make the bacteria resuspended.

(d) Add $200 \mu \mathrm{L}$ new solution II, mix it upside down, and ice bath is performed for Smin0. 
C5Gssense: 5'AACgAgAAggAg3

C5Gsantil: 5'ACTccgAggCAggAg3

C5Gmsensel: 5'AATCCgTTATATgCCTGA

C5Gssense2: 5'AACATggAGa

\begin{tabular}{|c|c|c|c|}
\hline $\mathrm{Gm}$ & & Gs & Contig5 \\
\hline C5Gssense: & $\longrightarrow$ & C5Gsantil: & $\longrightarrow$ \\
\hline
\end{tabular}

FIgURE 5: Schematic diagram of primer design.

(e) Add $150 \mu \mathrm{L}$ cold solution III, reverse and mix it well, and then take an ice bath of Smin0.

(f) Centrifuge for $s$ min at $12000 \mathrm{rpm}$ and $40^{\circ} \mathrm{C}$ and move the supernatant to a new pipe.

(g) Add solution of equal volume and the proportion of phenol and chloroform is $1: 1$, and shake and mix them. With the speed of $12000 \mathrm{rpm}$, centrifuge it for Smin. Then, the supernatant is moved to a new pipe.

(h) Add 2 times the volume of $95 \%$ cold ethanol, mix it upside down, and place it at room temperature for $30 \mathrm{~min}$.

(i) Centrifuge for $S_{\min }$ at $10000 \mathrm{rpm}$ and $4^{\circ} \mathrm{C}$.

(j) Supernatant is removed to add $1 \mathrm{ml} 70 \%$ ethyl alcohol and clean.

(k) Pour out the ethanol and dry it in the air.

(1) Dissolve it in $20 \mu \mathrm{L} \mathrm{TE}$, detect by $0.8 \%$ agarose gel electrophoresis (SV/cm voltage), and store it at $-20^{\circ} \mathrm{C}$.

Finally, PCR identification and positive clone were carried out.

PCR reaction system is shown in Table 5, and PCR reaction condition is shown in Table 6 .

Single colony was used as a template. PCR was used to complete the detection. Finally, the positive clone was completed.

\section{Experimental Inquiry}

In order to verify that the above methods can effectively improve the cloning effect, the comparative verification was carried out in the laboratory environment. Based on statistics division, the data of this experiment were tested by SAS8.1 software. According to Duncan, the significant difference was tested.

According to the previous research results in laboratory, an EST sequence was isolated from HarvEST database. Since the genomic database of Conringia planisiliqua was not published, RACE (Rapid amplification of cDNA ends) technology was used to amplify the third and fifth end of the sequence. The fragments with the
TABLE 5: Parameters of PCR reaction system.

\begin{tabular}{lc}
\hline Deionized water & $19.3 \mu \mathrm{L}$ \\
\hline $10 \times$ PCR buffer & $2.5 \mu \mathrm{L}$ \\
DNTP & $2.0 \mu \mathrm{L}$ \\
P3 & $0.5 \mu \mathrm{L}$ \\
P5 & $0.5 \mu \mathrm{L}$ \\
The template & A single colony \\
RTaq enzyme & $0.2 \mu \mathrm{L}$ \\
The total volume & $25 \mu \mathrm{L}$ \\
\hline
\end{tabular}

TABLE 6: PCR parameters of reaction condition.

\begin{tabular}{lc}
\hline Predenaturation at 95 degrees Celsius & $7 \mathrm{~min}$ \\
\hline 95 degree Celsius denaturation & $30 \mathrm{~s}$ \\
Annealing at $55^{\circ} \mathrm{C}$ & $30 \mathrm{~s}$ \\
Extension at $72^{\circ} \mathrm{C}$ & $1 \mathrm{~min} 35 \mathrm{~s}$ \\
Extension at $72^{\circ} \mathrm{C}$ & $7 \mathrm{~min}$ \\
The reaction ends at 4 degrees Celsius & \\
\hline
\end{tabular}

length of 254 and $153 \mathrm{Kbp}$ were obtained from 3'-end and 5'-end RACE PCR, respectively. Then, these two sequences were spliced with the original EST sequence to form a complete gene sequence that was verified by PCR. The total length of cDNA sequence is 428 by, including 141 by ORF and encoding forty-six amino acids. The amplified genome sequence was consistent with the full length of its cDNA sequence, so that the sequence contained only one exon without intron structure. When analyzing the possible domain of protein, the results show that this protein does not contain any known conserved domain, except for a repetitive structure composed of thirteen amino acids with low complexity.

ExPASY predicted that the relative molecular weight and isoelectric point of this protein were $4.94 \mathrm{kD}$ and 3.760 , respectively. Moreover, this sequence was imported into NCBI online database for BLAST analysis. We can see that this gene sequence is basically the same as that of an unidentified site geneLOC102619665 CXR 369802 in Conringia planisiliqua, and it also has about $77 \%$ sequence similarity with potential DNA binding protein CsV03-3 CEF175925. However, the homologous gene was not found in other species. The result of_L shows that the sequence was unique in citrus, so it is named FcSISP. Taking FcSISP as the data sample, we analyzed and compared the cloning effect of the designed gene cloning method. The statistical results are shown in Figures 6 and 7.

According to the above comparison result, for the cloning target of gene combination chain generated in the current laboratory, the designed cloning method is compared with TSA cloning method, multicomputer cloning method, and over-the-horizon cloning method. We can see that the designed cloning method has the lowest fitting index and more gene fragments per unit cycle. Thus, the effectiveness of the proposed method can be proved. 


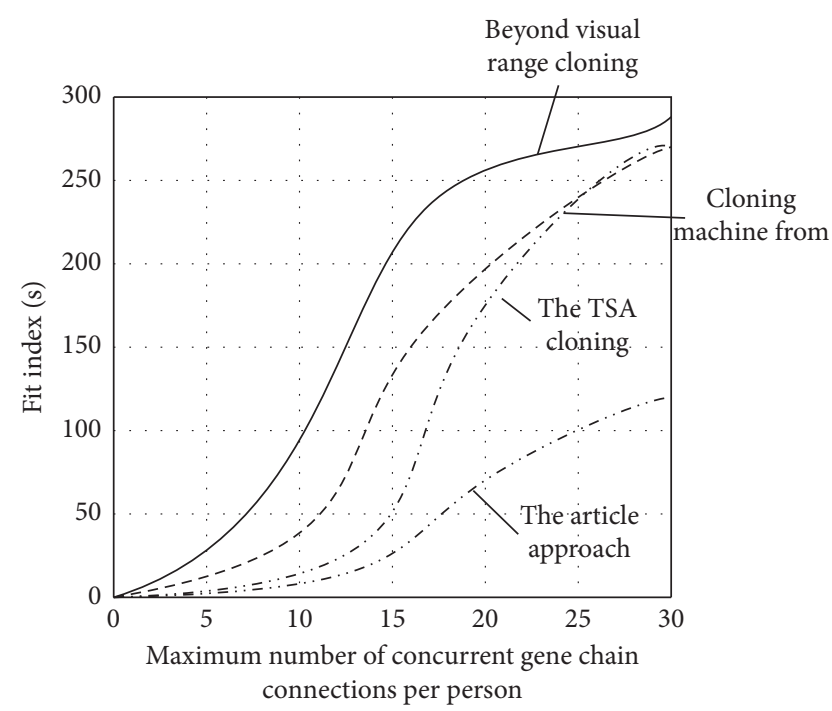

Figure 6: Comparison of the fitting index of multiple gene cloning methods.

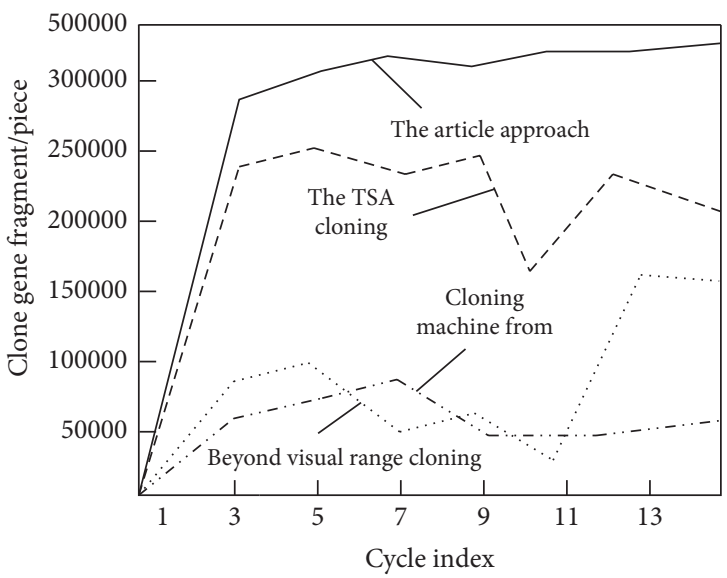

FIgURE 7: Comparison of maximum data storage of the system.

\section{Conclusions}

The analysis on the mRNA difference under the drought stress of Conringia planisiliqua of Conringia of Cruciferous ephemeral plant shows that eighteen gene segments induced or inhibited by drought are obtained. The proportion of hypothetical protein is $38.89 \%$. The proportion of diseaseresistant protein is $16.67 \%$. The proportion of unknown protein is $11.11 \%$. The proportion of photoperiod protein is $11.11 \%$. The proportion of basic metabolism is $5.56 \%$. The proportion of transcription factors is $16.67 \%$. On this basis, the result of gene cloning is better than that of the traditional method, which lays a foundation for gene cloning and functional verification of transcription factors, basic metabolism, and disease-resistant proteins in Conringia planisiliqua. This also provides a theoretical basis for the exploration of wild stress-resistant plant resource. Experimental results show that the proposed method can effectively reduce the gene data fitting and improve the quantity of gene fragments cloned in a cycle, so the overall cloning effect is better.

\section{Data Availability}

The data used to support the findings of this study are available upon request.

\section{Conflicts of Interest}

The authors declare no conflicts of interest.

\section{References}

[1] M. Lei, X. Wu, J. Zhang, H. Wang, and C. Huang, "Gene cloning, expression, and characterization of trehalose-6phosphate synthase from Pleurotus ostreatus," Journal of Basic Microbiology, vol. 57, no. 7, pp. 580-589, 2017.

[2] J. Kourelis and R. A. L. Van Der Hoorn, "Defended to the nines: 25 years of resistance gene cloning identifies nine mechanisms for R protein function," The Plant Cell, vol. 30, no. 2, pp. 285-299, 2018.

[3] Y. Wang, Z. Wang, X. Wang, Y. Duo, J. Chen, and J. Chen, "Gene cloning, expression, and reducing property enhancement of nitrous oxide reductase from Alcaligenes denitrificans strain TB," Environmental Pollution, vol. 239, pp. 43-52, 2018.

[4] T. Aung, H. Jiang, C. C. Chen et al., "Production, gene cloning, and overexpression of a laccase in the marine-derived yeast aureobasidium melanogenum strain 11-1 and characterization of the recombinant laccase," Marine Biotechnology, vol. 21, pp. 76-87, 2019.

[5] Z. Luo, S. Wang, B. Jiao et al., "Gene cloning and seamless sitedirected mutagenesis using single-strand annealing (SSA)," Applied Microbiology and Biotechnology, vol. 102, no. 23, pp. 10119-10126, 2018.

[6] L. Du, H. Jiang, G. Zhao, and J. Ren, "Gene cloning of ZmMYB59 transcription factor in maize and its expression during seed germination in response to deep-sowing and exogenous hormones," Plant Breeding, vol. 136, no. 6, pp. 834-844, 2017.

[7] Y. Xia, L. He, J. Mao, P. Fang, X.-Y. Ma, and Z. Wang, "Purification, characterization, and gene cloning of a new cold-adapted $\beta$-galactosidase from Erwinia sp. E602 isolated in northeast China," Journal of Dairy Science, vol. 4, no. 7, pp. 15-17, 2018.

[8] L. Y. Ding, M. Jin, P. Sun et al., "Cloning, tissue expression of the fatty acid-binding protein (Pt-FABP1) gene, and effects of dietary phospholipid levels on fabp and vitellogenin gene expression in the female swimming crab Portunus trituberculatus," Aquaculture, vol. 474, no. 8, pp. 57-65, 2017.

[9] W. Heng and C. Dandan, "Molecular cloning and induced expression of the plasma membrane intrinsic protein gene and promoter from mulberry (Morus multicaulis)," Canadian Journal of Plant Science, vol. 98, no. 5, pp. 5-7, 2018.

[10] E. B. Noy, M. K. Scott, S. V. H. Grommen, K. A. Robert, and B. De Groef, "Molecular cloning and tissue distribution of Crh and Pomc mRNA in the fat-tailed dunnart (Sminthopsis crassicaudata), an Australian marsupial," Gene, vol. 627, no. 14, pp. 26-31, 2017.

[11] P. Ratta, A. Kaur, S. Sharma, M. Shabaz, and G. Dhiman, "Application of blockchain and internet of things in healthcare and medical sector: applications, challenges, and future perspectives," Journal of Food Quality, vol. 2021, Article ID 7608296, 20 pages, 2021. 
[12] Y. Liu, B. Jiang, C. Fu, and R. Hao, "Cloning and characterization of adipogenin and its overexpression enhances fat accumulation of bovine myosatellite cells," Gene, vol. 601, no. 8, pp. 27-35, 2017.

[13] S. Raghavan, G. Venkatraman, and S. K. Rayala, "Cloning and functional characterization of human Pak1 promoter by steroid hormones," Gene, vol. 646, no. 9, pp. 120-128, 2017.

[14] J. M. B. Ricci, E. R. M. Martinez, A. J. Butzge et al., "Characterization of vasa homolog in a neotropical catfish, Jundiá (Rhamdia quelen): molecular cloning and expression analysis during embryonic and larval development," Gene, vol. 71, no. 7, pp. 13-18, 2018

[15] K. Y. Ma, S. F. Zhang, S. S. Wang, and G. F. Qiu, "Molecular cloning and characterization of a gonadotropin-releasing hormone receptor homolog in the Chinese mitten crab, Eriocheir sinensis," Gene, vol. 665, no. 8, pp. 111-118, 2018.

[16] D. Huo, X. Jiang, X. Wu et al., "First echinoderm trehalase from a tropical sea cucumber (Holothuria leucospilota): molecular cloning and mRNA expression in different tissues, embryonic and larval stages, and under a starvation challenge," Gene, vol. 665, no. 8, pp. 74-81, 2018. 